\title{
UJI AKTIVITAS ANTIAGING INVITRO LAVENDER BODY BUTTER
}

\author{
Nutrisia Aquariushinta Sayuti \\ Kementerian Kesehatan Politeknik Kesehatan Surakarta Jurusan Jamu
}

\begin{abstract}
Lavender, Body Butter, Antiaging. Antiaging product must contain antioxidant and sunscreens compound to protect skin from free radical. Lavender oil was a popular parfume of cosmetic form because of its antioxidant dan sunscreen activity. Body butter form was needed to increase antiaging activity of lavender oil. The study aimed to evaluate antiaging activity of lavender body butter trough antioxidant and sunscreen activity evaluation. Body butter was made from combination of lavender oil, olive oil, coconut oil beside cocoa butter. DPPH method was used to evaluate antioxidant activity, sunscreen activity was evaluated of the Sun Protection Factor value (SPF), the percentage of erythema transmission (\%Te) and percentage of pigmentation (\% Tp). The study showed that the body butter formula had IC50 of 56,34 ppm, 6,68 of \%Te, 16,34 of \%Tp and the SPF value was 10,88. The formula can increase lavender oil's antioxidant and sunscreen activity and it was need the addition of chemical sunscreen compound such as Zinci Oxyde or Titanium Oxyde. It can concluded body butter had strong antioxidant activity. It can protect the skin to againt $U V A$ ray but less protect from UVB and UVC rays.
\end{abstract}

Keywords : Lavender, Body Butter, Antiaging

Abstrak : Lavender, Body Butter, Antiaging. Produk antiaging untuk melawan radikal bebas biasanya mengandung antioksidan dan tabir surya sebagai bahan aktifnya. Minyak lavender merupakan parfum pilihan dalam formula kosmetika karena aktivitasnya sebagai antioksidan dan tabir surya. Pemilihan boddy butter sebagai sediaan kosmetika antiaging dirasa sangat tepat untuk meningkatkan aktivitas antiaging dari minyak lavender. Penelitian ini bertujuan untuk menguji aktivitas antiaging dari lavender body butter melalui uji aktivitas antioksidan dan tabir surya secara invitro. Boddy butter dibuat dengan mengkombinasikan minyak lavender bersama minyak kelapa dan minyak zaitun selain oleum cacao. Aktivitas antioksidan diuji menggunakan metode DPPH sedangkan aktivitas tabir surya dilakukan melalui penetapan nilai Sun Protection Factor (SPF), persentase transmisi eritema (\% Te) dan persentase transmisi pigmentasi (\%Tp). Hasil penelitian menyebutkan bahwa formula body butter mempunyai IC50 56,34 ppm, \%Te 6,68, \%Tp 16,34 dan nilai SPF sebesar 10,88. Formula mampu meningkatkan aktivitas antioksidan dan tabir surya dari minyak lavender dan perlu ditambahkan zat tabir surya kimia seperti Seng Oksida atau Titanium Oksida pada penelitian formulasi berikutnya. Kesimpulannya adalah aktivitas antioksidan body butter adalah antioksidan kuat dan mampu melindungi kulit dari UVA tetapi belum mampu melindungi kulit dari sinar UVB dan UVC.

Kata Kunci : Lavender, Body Butter, Antiaging 


\section{PENDAHULUAN}

Penggunaan obat tradisional dan suplemen makanan cenderung meningkat akibat dari kecenderungan gaya hidup back to nature dan hal ini banyak disikapi oleh industri farmasi untuk memproduksi sediaan farmasi yang berbasis tanaman obat atau bahan alam (Gusmali dan Gitawati, 2001). Beberapa manfaat tanaman obat di bidang medis dan estetika antara lain sebagai analgesik, antihistamin, imunomodulator, antikanker, antibakteri, antioksidan, tabir surya, pelembab dan antiselulit (SkidmoreRoth,2010). Antioksidan dan tabir surya lebih banyak dibahas dalam hal manfaat tanaman obat sebagai agen anti penuaan (antiaging). Penuaan (aging) merupakan proses biologis yang kompleks yang disebabkan oleh faktor instrinsik (dari dalam tubuh seperti genetic) dan faktor ekstrinsik (dari lingkungan). Faktor ekstrinsik yang paling berperan dalam penuaan adalah radikal bebas dan paparan sinar ultraviolet (UV) dari matahari.

Peningkatan populasi yang mengalami penuaan dini dan efek terhadap psikososial telah menciptakan permintaan untuk melawan penuaan pada kulit, salah satunya adalah produk cosmeceutical anti aging. Produk anti aging yang digunakan untuk melawan penuaan yang disebabkan oleh radikal bebas mengandung antioksidan dan tabir surya sebagai bahan aktifnya. Antioksidan mampu meningkatkan hidrasi kulit, elatisitas dan produksi sebum serta meningkatkan kemampuan fisiologis kulit dalam menangkal kerusakan kulit akibat radikal bebas dan sinar UV. Penggunaan kombinasi dari beberapa senyawa antioksidan yang berasal dari tanaman obat (phytoantioxidant) merupakan strategi perlindungan terbaik dari radikal bebas dan sinar UV sehingga penentuan aktivitas antioksidan dan aktivitas tabir surya dari kombinasi beberapa bahan tanaman obat merupakan pendekatan terbaik untuk meningkatkan inovasi formula kosmetika antiaging (Mishra, 2011).

Bunga lavender (Lavandula angustifolia) merupakan tanaman asli Swiss dan telah banyak dimanfaatkan sebagai pembuatan lotion anti nyamuk karena memiliki zat linalool dan Lynalyl asetat yang sangat tidak disukai oleh nyamuk. Minyak lavender (Oleum Olivarum) memiliki banyak potensi sebagai antiaging diantaranya adalah anticemas, antibakteri, membersihkan kulit, detoksifikasi kulit, menyembuhkan luka bakar, mencerahkan kulit, antioksidan kuat dan meringankan eksim dan psoriasis. Minyak lavender sebanyak 10 tetes yang dicampur dengan $130 \mathrm{ml}$ gel lidah buaya atau minyak kelapa (coconut oil) memiliki manfaat besar pada kulit yaitu mengurangi luka bakar akibat sengatan matahari dan membuat luka cepat kering (Anonim, 2016). Penelitian yang dilakukan oleh Kaur dan Saraf pada tahun 2010 tentang penentuan nilai SPF (Sun protection factor) sediaan kosmetika yang mengandung minyak herbal memberikan hasil bahwa nilai SPF untuk minyak lavender sebesar 5,624. Hal tersebut menyebabkan minyak lavender merupakan parfum pilihan dalam formula kosmetika baik sediaan cream mau pun lotion (Saraf dan Kaur, 2010).

Pemilihan formula kosmetika dalam bentuk sediaan cream mau pun lotion merupakan salah satu upaya untuk menambahkan nilai jual dari minyak lavender. Kelebihan sediaan ini adalah sifatnya yang menyenangkan dan mampu meningkatkan hidrasi dan kelembaban 
kulit. Seringkali kita mendengar tentang istilah body lotion, body cream, body butter atau body milk. Dari segi viskositas, body milk lebih cair dari sediaan lainnya sedangkan body butter paling kental. Boddy butter paling banyak mengandung minyak, tekstur lebih kental mirip margarin atau mentega. Boddy butter lebih cocok dioleskan pada bagian tubuh yang sangat kering seperti siku, lutut dan tumit. Kandungan di dalam body butter biasanya adalah sea butter, cocoa butter atau coconut butter yang mengandung minyak lemak dengan tingkat yang cukup tinggi (Ive, 2016). Penggunaan minyak nonvolatile dalam formula body butter juga dapat meningkatkan aktivitas tabir surya dari sediaan kosmetik. Saraf dan Kaur melaporkan dalam penelitiannya bahwa nilai SPF beberapa minyak nonvolatile lebih tinggi dari pada minyak volatile. Nilai SPF dari minyak zaitun (oleum olivarum) adalah 7,549 sedangkan nilai SPF dari minyak kelapa (oleum cocos) adalah 7,119 (Saraf dan Kaur, 2010)

Hal tersebut diatas yang menyebabkan peneliti tertarik untuk menguji aktivitas antiaging minyak lavender dalam sediaan body butter melalui uji aktivitas antioksidan dan penentuan nilai transmisi eritema, persetase transmisi eritema (\% $(\%)$, persentase transmisi pigmentasi (\% $\%$ p) dan nilai SPF. Formula basis boddy butter dibuat dengan memanfaatkan kemampuan tabir surya dari oleum olivarum dan minyak kelapa oleum cocos yang diharapkan dapat meningkatkan perolehan nilai SPF dari minyak lavender.

\section{METODE PENELITIAN}

Penelitian ini merupakan penelitian observasional. Minyak lavender sebanyak 0,5 gram ditambahkan pada basis body butter yang mengandung aloe vera ekstrak sebanyak $1 \%$ hingga diperoleh berat sebanyak 100,0 gram. Formula lavender body butter dapat dilihat pada tabel 1 .

Tabel 1

Formula Lavender Body Butter

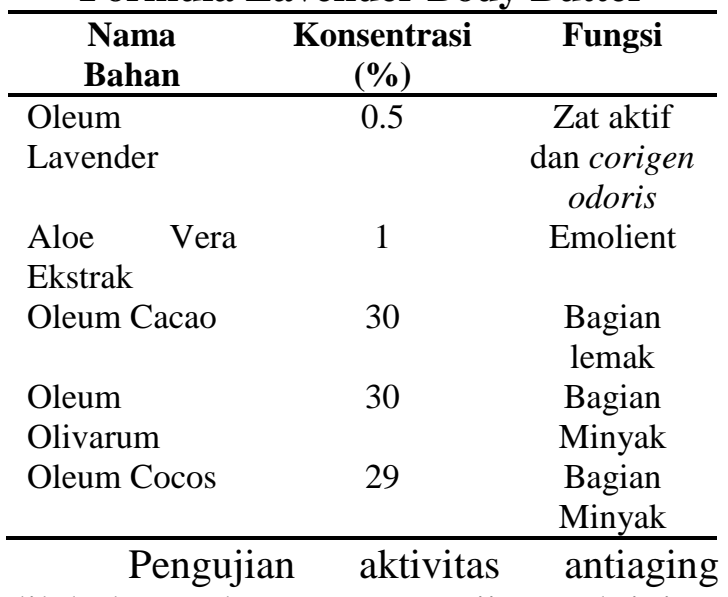

dilakukan dengan pengujian aktivitas antioksidan dan penentuan \% Te, \% Tp dan nilai SPF secara invitro. Uji aktivitas antioksidan dilakukan melakukan pengenceran body butter menggunakan ethanol $96 \%$ dengan membuat variasi konsentrasi 20 ppm, 80 ppm, 100 ppm. Masing-masing larutan konsentrasi diambil $2 \mathrm{ml}$ direaksikan dengan $1 \mathrm{ml}$ larutan DPPH 100 ppm. Larutan blangko digunakan $2 \mathrm{ml}$ larutan ethanol 96\% dan direaksikan dengan $1 \mathrm{ml}$ larutan DPPH $100 \mathrm{ppm}$. Semua sampel dibuat triplo, kemudian, diinkubasi selama 30 menit pada suhu $27^{0}$ C. sampel yang telah diinkubasi diuji nilai absorbansinya pada panjang gelombang $517 \mathrm{~nm}$ dengan menggunakan spektrofotometer UV-Vis. Aktivitas antioksidan dihitung melalui penentuan persen inhibisi dengan rumus : 


$$
\text { Persen inhibisi }=\frac{A_{c}-A}{A_{c}}
$$

Keterangan : $A_{c}=$ Nilai absorbansi control, $\mathrm{A}=$ Nilai absorbansi sampel

Dari persen inhibisi kemudian ditentukan konsentrasi Inhibisi 50\% (IC50) melalui persamaan regresi linear y $=\mathrm{bx}+\mathrm{C}$, dimana y adalah persen inhibisi sedangkan $\mathrm{x}$ adalah konsentrasi bodybutter.

Suatu senyawa dikatakan sebagai antioksidan sangat kuat jika nilai IC50 kurang dari 50ppm, kuat (50 ppm -100 ppm), sedang (100 ppm-150ppm), dan lemah (151 ppm-200 ppm). Semakin kecil nilai IC semakin tinggi aktivitas antioksidan. (Badarinath, 2010).

Untuk penentuan nilai SPF, \% Te dan \%Tp dilakukan dengan cara menimbang body butter sebanyak 0,1 gram kemudian dilarutkan dengan ethanol 96\% sebanyak $10 \mathrm{ml}$. Penentuan nilai SPF, dilakukan dengan cara larutan dibuat kurva serapan dengan panjang gelombang dari $290-320 \mathrm{~nm}$, ethanol digunakan sebagai blangko (Sayre et al., 1979 dalam Setiawan T, 2010). Nilai serapan dicatat setiap interval $5 \mathrm{~nm}$. Nilai SPF sediaan dihitung dengan rumus:

$$
\begin{gathered}
\mathrm{SPF}=\mathrm{CF} \times \sum_{290}^{320} E E(\lambda) \times \mathrm{I}(\lambda) \mathrm{x} \\
\text { absorbansi }(\lambda)
\end{gathered}
$$

Keterangan : $\mathrm{CF}=$ Faktor Korelasi (10),

$\mathrm{EE}=$ Efisiensi Eriterma, I = Spektrum Simulasi Sinar Surya.

Nilai EE $x \quad I$ adalah suatu konstanta. Nilainya telah ditentukan oleh Sayre et al, 1979 seperti yang terlihat dalam tabel di bawah ini:
Tabel 2

Nilai EE x I pada Panjang Gelombang

$290-320 \mathrm{~nm}$

\begin{tabular}{cc}
\hline $\begin{array}{c}\text { Panjang gelombang } \\
(\lambda \mathrm{nm})\end{array}$ & EE x I \\
\hline 290 & 0,0150 \\
295 & 0,0817 \\
300 & 0,2874 \\
305 & 0,3278 \\
310 & 0,1864 \\
315 & 0,0839 \\
320 & 0,0180 \\
Total & 1 \\
\hline
\end{tabular}

Sumber : Setiawan T, 2010

Berikut merupakan penilaian nilai SPF menurut Food and Drug

Administration (FDA)

\section{Tabel 3}

Penilaian SPF menurut FDA

\begin{tabular}{lc}
\hline \multicolumn{1}{c}{ Tipe Proteksi } & Nilai SPF \\
\hline Proteksi minimal & $1-4$ \\
Proteksi sedang & $4-6$ \\
Proteksi ekstra & $6-8$ \\
Proteksi maksimal & $8-15$ \\
Proteksi ultra & $>15$ \\
\hline
\end{tabular}

Sumber : Charisma L, 2012

Penentuan persen eritema dan persen pigmentasi dilakukan dengan mengukur absorbansi larutan pada panjang gelombang 292,5 - 372,5 nm kemudian dihitung nilai serpan dan nilai transmitannya dengan rumus $\mathrm{A}=-\log \mathrm{T}$. Nilai transmisi eritema dihitung dengan cara mengalikan nilai transmisi (T) dengan factor efektivitas eritema $(\mathrm{Fe})$ pada $\lambda=292,5-372,5 \mathrm{~nm}$. Nilai transmisi pigmentasi dihitung dengan cara mengalikan nilai transmisi ( $\mathrm{T}$ ) dengan factor efektivitas pigmentasi (Fp) pada $\lambda=292-372 \mathrm{~nm}$. Selanjutnya nilai persen eritema dihitung dengan rumus :

$$
\% \mathrm{Te}=\frac{\sum\left(\mathrm{TxFe}_{\mathrm{e}}\right)}{\sum \mathrm{Fe}} \% \mathrm{Tp}=\frac{\sum(\mathrm{TxFp})}{\sum \mathrm{Fp}}
$$


Keterangan : \% $\mathrm{Te}=$ nilai persen tranmisi eritema, $\% \mathrm{Tp}=$ Nilai persen transmisi pigmentasi, $\mathrm{Ee}=\sum(\mathrm{T} \times \mathrm{Fe}), \mathrm{Ep}=\sum(\mathrm{T} x$ $\mathrm{Fp})$

Berikut ini merupakan nilai dari fluks eritema (FE) dan fluks pigmentasi (Fp) untuk sediaan tabir surya.

\section{Tabel 4.}

Transmisi Eritema dan Pigmentasi Sediaan Tabir Surya

\begin{tabular}{cr}
\hline $\begin{array}{c}\text { Rentang Panjang } \\
\text { Gelombang (nm) }\end{array}$ & Fluks Eritema \\
\hline $290-295$ & 0,1105 \\
$295-300$ & 0,6720 \\
$300-305$ & 1,0000 \\
$305-310$ & 0,2008 \\
$310-315$ & 0,1364 \\
$315-320$ & 0,1125 \\
Rentang total & 2,2322 \\
$290-320 \mathrm{~nm}$ & $(76,3 \%)$ \\
\hline Rentang Panjang & Fluk \\
Gelombang (nm) & 0,1079 \\
$320-325$ & 0,1020 \\
$325-330$ & 0,0936 \\
$330-335$ & 0,0798 \\
$335-340$ & 0,0669 \\
$340-345$ & 0,0570 \\
$345-350$ & 0,0488 \\
$350-355$ & 0,0456 \\
$355-360$ & 0,0356 \\
$360-365$ & 0,0310 \\
\hline $365-370$ & 0,0260 \\
$370-375$ & 0,6942 \\
Rentang total & $(23,7 \%)$ \\
pligmentasi, $290-375 \mathrm{~nm}$ & 2,9264 \\
\hline & $(100 \%)$ \\
\hline pigmentasi $320-375 \mathrm{~nm}$ &
\end{tabular}

Tabel 5.

Kategori Penilaian Tabir Surya

\begin{tabular}{ccc}
\hline \% & \% & $\begin{array}{c}\text { Kategori Penilaian } \\
\text { Tabir Surya }\end{array}$ \\
\hline$<1$ & $3-40$ & Sunblock \\
$1-6$ & $42-86$ & Proteksi Ultra \\
$6-12$ & $45-86$ & Suntan \\
$10-18$ & $45-86$ & Fast tanning \\
\hline
\end{tabular}

Analisa data dilakukan secara univariat dengan mendiskripsikan hasil rata-rata perhitungan $\mathrm{CI} 50$, nilai $\mathrm{SPF}$, $\% \mathrm{Te}$ dan \% $\mathrm{Tp}$ dalam suatu tabel kemudian dilakukan pembahasan.

\section{HASIL PENELITIAN}

Boddy butter merupakan sediaan kosmetika yang berfungsi untuk mencegah dehidrasi kulit karena kandungan minyaknya yang tinggi. Potensi body butter sebagai sediaan kosmetika antiaging sangat bagus karena kandungan minyak volatile yang tinggi tersebut memungkinkan body butter lebih bermanfaat bagi pelindung kulit dari paparan sinar UV. Dalam penelitian ini, formulasi boddy butter dilakukan dengan mengkombinasikan potensi tabir surya dan antioksidan dari oleum olivarum, oleum cocos dan oleum lavender sehingga digunakan ketiga minyak tersebut kemudian hasil formula diuji aktivitas anti aging melalu pengujian aktivitas antiosidan dan tabir surya.

Pengujian aktivitas antioksidan dilakukan secara invitro dengan menggunakan metode peredaman radikal bebas 1,1-difenil-2-pikrilhidrazil (DPPH). DPPH merupakan radikal bebas yang stabil pada suhu kamar dan sering digunakan untuk menilai aktivitas antioksidan senyawa atau ekstrak bahan alam. Interaksi antioksidan dengan DPPH baik secara transfer electron atau radikal hydrogen pada DPPH akan menetralkan karakter radikal bebas dari DPPH. Jika semua electron pada radikal bebas DPPH menjadi berpasangan, maka warna larutan berubah dari ungu tua menjadi kuning terang dan absorbansi pada panjang gelombang $517 \mathrm{~nm}$ akan hilang (Green, 2004; Gurav et al, 2007 dalam Erawati, 2012). 
Efek buruk dari paparan sinar UV dari matahari ditandai dengan warna kemerahan pada kulit (eritema) yang diikuti warna coklat kemerahan. Warna coklat kemerahan pada dasarnya merupakan reaksi perlindungan kulit terhadap kerusakan kulit akibat paparan sinar UV (Balsam dan Saragin, 1972). Kulit yang terpapar sinar matahari selama 6-20 jam akan mengakibatkan warna cokelat (tanning). Tanning dibagi menjadi dua tipe, yaitu tanning cepat yang akan nampak terlihat selama 1 jam setelah kulit terpapar, dan akan hilang setelah 4 jam kemudian. Hal ini terjadi karena adanya reaksi oksidasi dan radikal bebas semiquinon yang terjadi didalam melanin. Tanning lambat terjadi 48-72 jam setelah paparan sinar matahari pada panjang gelombang berkisar antara 320$500 \mathrm{~nm}$. Sedangkan pada sunburn terjadi pada panjang gelombang $290-320 \mathrm{~nm}$, hal ini terjadi sangat lambat berkisar 72 jam kemudian karena adanya pembentukan melanosom baru (Maulidia, 2010). Untuk mengukur kemampuan sediaan tabir surya dari pencegahan terbentuknya eritema dan pigmentasi dilakukan secara invitro dengan penentuan nilai $\mathrm{SPF}, \% \mathrm{Te}$ dan $\% \mathrm{Tp}$.

Hasil aktivitas antiaging lavender body butter dapat dilihat pada tabel berikut:

\section{Tabel 6}

Hasil Uji Aktivitas Antiaging Lavender Body Butter

\begin{tabular}{ccc}
\hline Pengujian & $\begin{array}{c}\text { Nilai } \\
\text { (mean } \pm \text { SD) }\end{array}$ & Kategori \\
\hline IC50 & $56,34 \mathrm{ppm} \pm$ & Antioksidan kuat \\
& 12,12 & \\
$\% \mathrm{Te}$ & $6,68 \pm 0,18$ & Suntan \\
$\% \mathrm{Tp}$ & $16,30 \pm 0,56$ & Sunblok \\
$\mathrm{SPF}$ & $10,88 \pm 0,11$ & Proteksi ekstra \\
\hline
\end{tabular}

Pengujian terhadap aktivitas antioksidan body butter menghasilkan nilai IC50 dengan kategori antioksidan kuat. Menurut penelitian yang dilakukan oleh Asmarani FC dan Wahyuningsih pada tahun 2015 memberikan hasil bahwa aktivitas minyak zaitun yang diformulasikan menjadi sediaan nanoemulsi dengan variasi konsentrasi Tween 80 dan Sorbitol memiliki nilai IC50 77,37 ppm - 576,69 ppm. Kekuatan aktivitas antioksidannya lebih lemah 1,5 sampai 10 kali dari minyak zaitun yang memiliki nilai IC50 $\pm 55,79$ ppm (Asmarani dan Wahyuningsih, 2015). Sedangkan penelitian yang dilakukan oleh Malika dan Imene pada tahun 2012, menyatakan hasil bahwa minyak lavender memiliki aktivitas antioksidan dengan besar IC50 584 $\pm 0,58$ ppm. Dalam penelitian mengenai lavender body butter ini terjadi peningkatan aktivitas antioksidan karena kombinasi dari minyak lavender, minyak zaitun dan minyak kelapa dengan penurunan nilai IC50 sebesar 56,34 ppm dan masuk antioksidan kuat.

Kaur dan Saraf pada tahun 2010 dalam penelitiannya tentang penentuan nilai SPF memiliki hasil bahwa nilai SPF untuk minyak lavender, minyak zaitun dan minyak kelapa berturut-turut sebesar 5,624 ; 7,549 dan 7,119 (Saraf dan Kaur, 2010). Formulasi lavender body butter telah meningkatkan aktivitas tabir surya dari kombinasi ketiga minyak dengan peningkatan nilai SPF sebesar 10,88 dan masuk pada kategori tabir surya dengan proteksi ekstra. Akan tetapi dari hasil penentuan \%Te, sediaan body butter belum dapat memenuhi ketentuan dari nilai tabir surya yang minimal berkategori proteksi ultra. Hasil penentuan \% Tp sudah 
memenuhi syarat body butter sebagai sediaan tabir surya.

Pernyataan yang dikemukakan oleh Agustin et al pada tahun 2013 dalam penelitannya menyatakan bahwa penentuan aktivitas tabir surya berupa nilai SPF, \% Transmisi Eritema dan \% Transmisi Pigmentasi. Penentuan nilai SPF dan \% Te digunakan untuk menunjukkan perlindungan terhadap sinar UV-B, sedangkan \% Tp digunakan untuk menunjukan perlindungan terhadap sinar UV-A. Dari hasil pengujian aktivitas tabir surya sediaan body butter memberikan hasil bahwa sediaan efektif meberikan perlindungan terhadap UVA tetapi kurang efektif dalam memberikan perlindungan terhadap sinar UVB.

\section{PEMBAHASAN}

Sinar UV adalah salah satu sinar yang dipancarkan matahari hingga mencapai bumi selain sinar tampak dan sinar inframerah. Sinar UV memiliki panjang gelombang antara 200-400 nm. Spektrum sinar UV terbagi atas 3 kelompok yang dibagi berdasarkan panjang gelombangnya, yaitu gelombang UV C dengan panjang gelombang antara 200-290 nm, sinar UV B dengan panjang gelombang berkisar antara 290-320 nm, dan sinar UV A dengan panjang gelombang antara 320-400 nm. Namun, sinar UV A dibagi menjadi 2 kelompok, yaitu sinar UV A 2 dengan panjang gelombang antara 320-240 nm, dan sinar UV A 1 dengan panjang gelombang antara 340-400 nm (Colipa, 2006). Sinar UV B adalah sinar ultraviolet yang lebih banyak berpengaruh dalam merusak kulit dibandingkan dengan sinar UV A atau sinar UV C, karena sinar UV B memiliki kekuatan 1000 kali lipat lebih kuat daripada sinar UV A dan UV C dalam proses pembentukan eritema pada kulit (McKinlay \& Diffey, 1987). Berdasarkan paparan diatas, untuk meningkatkan aktivitas sediaan tabir surya dari sediaan boddy butter disarankan perlunya ditambahkan zat tabir surya kimia seperti Seng Oksida atau Titanium Oksida pada penelitian formulasi berikutnya.

\section{KESIMPULAN DAN SARAN}

Kesimpulan dari penelitian ini adalah aktivitas antiaging dari lavender body butter yang diuji melalui pengujian aktivitas antioksidan dan aktivitas tabir surya memiliki aktivitas antioksidan kuat (IC50 $= \pm 56,34 \mathrm{ppm})$ dan mampu melindungi kulit dari sinar UVA dengan nilai $\% \mathrm{Tp} \pm 16,30$ tetapi belum mampu melindungi kulit dari sinar UVB dan UVC yang dilihat dari nilai SPF sebesar $\pm 10,88$ dan \%Te sebesar 16,68 . Untuk penelitian selanjutnya perlu penambahan zat tabir surya kimia untuk meningkatkan aktivitas tabir surya dari lavender body butter.

\section{DAFTAR RUJUKAN}

Agustin R, dkk. 2013. Formulasi Krim Tabir Surya dari Kombinasi Etil pMetoksisinamat dengan Katekin. Prosiding Seminar Nasional Perkembangan Terkini Sains Farmasi dan Klinik III 2013 Fakultas Farmasi Universitas Andalas.

Anonim. 2016. 7 manfaat penyembuhan lavender essential oil (Minyak lavender).http://www.atsirich.com/ 24/7-manfaat-penyembuhan lavender-essential-oil-minyaklavender/, diakses : 25 Januari 2017

Asmarani dan Wahyuningsih. 2015. Pengaruh Variasi Konsentrasi Tween 80 dan Sorbitol Terhadap 
Aktivitas Antioksidan Minyak Zaitun (Oleum Olivae) dalam Formulasi Nanoemulsi. Farmasains Vol 2 No. 5.

Balsam, M. S., \& Sagarin, E. (Eds.). 1972. Cosmetics: Science and technology 2nd Ed., Vol. 1-3. New York: Interscience Publishers, Inc.

Colipa. 2006. Guideline for efficacy Test. European: COLIPA

Charisma, S. L. 2012. Daya Tabir Surya dan Antioksidan Formula Krim Ekstrak Rimpang Kencur (Kaempferia galanga L) dan Rimpang Temu Kunci (Boesenbergia pandurata (Roxb.) Schlecht). Purwokerto: Universitas Muhammadiyah

Erawati. 2012. Uji Aktivitas Antioksidan Ekstrak Daun Garcinia daedalantera dengan Metode DPPH dan Identifikasi Senyawa Kimia dari Fraksi Paling Aktif. Fakultas Matematika dan Ilmu Pengetahuan Alam. Depok: Universitas Indonesia.

Gusmali, D dan Gitawati R. 2001. Kajian Keamanan Beberapa Food Supplement yang beredar di tiga kota besar berdasarkan informasi dari penandaan dan pengalaman konsumen. Laporan Penelitian Puslitbang Farmasi. Badan Litbang Kesehatan.

Ive. 2016. Perbedaan Body Lotion, Body Cream, Body Butter dan Body Milk. http://beautynesia.id/4856, diakses 25 Januari 2017

Kaur CD, Saraf S. 2010. In vitro sun protection factor determination of herbal oils used in cosmetics.
Pharmacognosy ; Vol 2 No.1 : 225.

Maulidia, SO. 2010.Uji efektivitas dan fotostabilitas krim ekstrak ethanol 70\% Teh Hitam (Camellia sinensis L.) sebagai Tabir Surya secara In Vitro. Jakarta : Fakultas Kedokteran dan Ilmu Kesehatan UIN Syarif Hidayatullah.

McKinlay, A. and Diffey , B. 1987. A Reference Spectrum for Ultraviolet Induced Erythema in Human Skin. CIE J, Vol 6 No.1 : $17-22$

Mishra K, et-al. 2011. Herbal Cosmeceuticals for Photoprotection from Ultraviolet B Radiation: A Review. Tropical Journal of Pharmaceutical Research June 2011; Vol 10 No. 3 : 351-360

More, B. H, S. N. Sakharwade, S. V. Tembhurne, D.M. Sakarkar. 2013. Evaluation of Sunscreen Acvtivity of Cream containing Leaving Extract of Butea monosperma for Topical application. Dept. Pf Cosmetic Technology, Seminary Hills, Nagpur, India

Setiawan T. 2010. Uji Stabilitas Fisik dan Penentuan Nilai SPF Krim Tabir Surya Yang Mengandung Ekstrak Daun The Hijau (Camellia sinensis L.), Oktil Metoksinamat dan Titanium Dioksida. Fakultas Matematika dan Ilmu Pengetahuan Alam. Program Sarjana Farmasi. Depok : Universitas Indonesia.

Skidmore-Roth, 2010. Mosby's Handbook of Herbs \& Natural Supplements, 4th Edition. Elsevier Mosby. 